\title{
NEPP - NUCLEO DE EXTENSÃO E PRÁTICA PROFISSIONAL
}

Maria Cleide Ribeiro de Oliveira ${ }^{1}$ Gabriela Almeida Araújo ${ }^{2}$

\section{RESUMO}

O Núcleo de Extensão e Prática Profissional - NEPP - é um projeto, sem fins lucrativos, que surgiu no ano de 2009, com o intuito de suprir as demandas de prática profissional, na área da construção civil para os alunos do IFRN. De acordo com o Projeto Político Pedagógico do IFRN, o NEPP, além de proporcionar a prática profissional aos alunos da DIACON (Diretoria Acadêmica de Construção Civil), também oferece serviços técnicos na área de arquitetura e engenharia civil, de forma gratuita, à comunidade carente, instituições filantrópicas, além de servidores e alunos do Instituto. Os alunos atuantes nesse projeto desenvolvem atividades relativas à sua formação técnica utilizando softwares como o AutoCAD, o Sketchup e o Revit Architecture.

Palavras-chave: IFRN, Prática Profissional, Construção Civil.

\section{INTRODUÇÃO}

O Núcleo de Extensão e Prática Profissional é uma entidade vinculada à DIACON do Instituto Federal de Educação, Ciência e Tecnologia do Rio Grande do Norte. Esse projeto surgiu como uma nova alternativa de prática profissional para os alunos do curso de Edificações do Campus Natal-Central (CNAT) do IFRN, associada a pouca disponibilidade de órgãos que ofereçam serviços técnicos gratuitos à comunidade socialmente carente.

Desde sua criação, em 2009, o NEPP já atendeu a 106 famílias e 4 instituições filantrópicas, sendo 33 o número total de beneficiados até o ano de 2011, 65 durante o ano de 2012, e 11 famílias e a Escola Ambulatório Padre João Maria (que atende a 503 crianças) em 2013. Nesse processo, 21 alunos também foram beneficiados com a prática profissional.

Dessa forma, os serviços prestados e os benefícios oferecidos ao público interno e a comunidade, até o presente momento, por si só, já justificam a continuidade, o desenvolvimento e a execução deste projeto.

\section{NÚCLEO DE EXTENSÃO E PRÁTICA PROFISSIONAL - NEPP}

O Projeto Político Pedagógico do IFRN diz que:

a função social desta Instituição é ofertar educação profissional e tecnológica com-

1 Professora da Diretoria de Construção Civil do Campus Natal Central.

2 Aluna do curso técnico em edificações, bolsista do projeto. 
prometida com a formação humana integral, com o exercício da cidadania e com a produção e a socialização do conhecimento, visando, sobretudo, a transformação da realidade na perspectiva da igualdade e da justiça sociais. (IFRN, 2012, p.21)

Eainda, afirma que as práticas extensionistas constituem ações mediadoras entre teoria e prática, ampliando a formação ou a qualificação profissional de estudantes e de educadores em geral, bem como contribuindo como via de interação com a sociedade, tanto para o Instituto conhecer a realidade sociocultural, econômica e política do seu entorno quanto para a comunidade ter acesso ao saber produzido no e pelo Instituto. (IFRN, 2012, p. 190-191)

Nesse contexto, o NEPP tem como objetivo principal oferecer aos discentes e docentes da Diretoria de Construção Civil a oportunidade de difusão da prática profissional, através de um escritório-modelo que traz o mundo do trabalho para dentro da Instituição de ensino oferecendo a comunidade serviços técnicos de qualidade realizados por técnicos em formação, orientados por professores e também profissionais experientes na área de construção civil.

0 aluno desenvolve atividades relativas à sua formação profissional, como visitas e levantamentos técnicos, projetos de engenharia e atendimento ao público com consultorias em geral. Tendo a oportunidade de pôr em prática o que aprenderam nas disciplinas técnicas em sala de aula, incorporando o aperfeiçoamento e a ampliação dos conhecimentos adquiridos nessas práticas ao processo ensino-aprendizagem.

Ao mesmo tempo que os técnicos em formação realizam sua prática profissional, serviços nas áreas de arquitetura e engenharia civil - como projetos arquitetônicos, de instalações elétricas, hidrossanitárias e orçamentos - são oferecidos à comunidade.

Com isso, podemos constatar que o NEPP constitui um projeto integrador das disciplinas técnicas lecionadas no curso técnico em edificações, interligando a extensão ao ensino.

\section{COMO FUNCIONA O NEPP}

O NEPP funciona atualmente nas dependências do IFRN, inserido na Diretoria de Construção Civil (DIACON), com estrutura física de escritório modelo básico, constituído de quatro computadores, para uso dos técnicos em formação e um computador do professor orientador, além de plotter, scanner, telefone/fax e mobília de apoio, como apresentado na Figura 1.

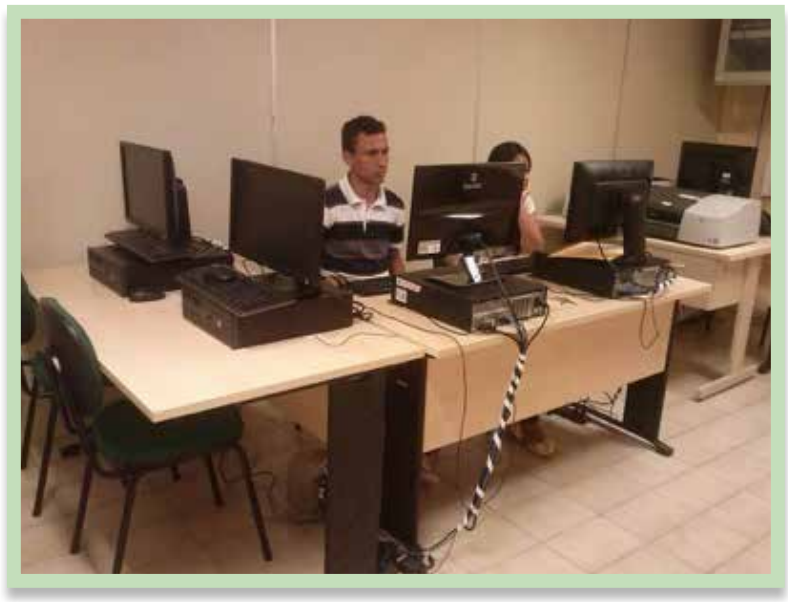

Figura 1: NEPP/DIACON/IFRN

A metodologia utilizada na proposta deste projeto tem por base o próprio exercício da prática profissional com a orientação do professor para a confecção de trabalhos técnicos que atendam, principalmente, à comunidade carente e instituições filantrópicas.

Para a comunidade externa ter acesso aos serviços técnicos, a pessoa interessada deverá se conduzir ao NEPP para realização de cadastro, quando irá transmitir informações sobre o imóvel, objeto de trabalho, sua localização e acessibilidade, além de dados pessoais do proprietário, inclusive sua incapacidade financeira de contratar profissionais técnicos habilitados. Poderão ser beneficiários com os serviços oferecidos pelo NEPP, pessoas físicas com renda familiar de até 3 salários mínimos, instituições filantrópicas, além de servidores e alunos do IFRN, de forma gratuita.

Semanalmente, são realizadas visitas técnicas para levantamentos, medições e coleta de dados necessários para confecção do trabalho solicitado, por parte dos alunos, sob a supervisão e orientação de professores.

O coordenador deste projeto de extensão se responsabiliza em articular as demandas existentes às atividades desempenhadas, bem como acompanhar a produtividade dos alunos envolvidos, além de outros procedimentos administrativos. Os principais serviços técnicos desempenhados pelos alunos no NEPP são:

- Levantamentostécnicos de informações físicas de edifícios já construídos para a produção de desenhos arquitetônicos;

- Plantas e croquis de engenharia em geral;

- Projetos de arquitetura para construção 
e/ou reforma;

- Projetos de instalações elétricas;

- Projetos de instalações hidrossanitárias;

- Levantamento de quantitativos e orçamento;

- Plotagem de plantas elaboradas em CAD - Desenho Assistido por Computador.

O resultado dessa produção são projetos impressos como podemos visualizar na figura 2 .

\section{CONCLUSÃO}

O NEPP representa atualmente uma boa alternativa de prática profissional aos alunos da Diretoria de Construção Civil, contribuindo positivamente com as demandas de apoio a formação técnica e ainda, presta serviços técnicos à comunidade externa, apoiando o IFRN no seu retorno à sociedade de todo o saber difundido no ambiente escolar.

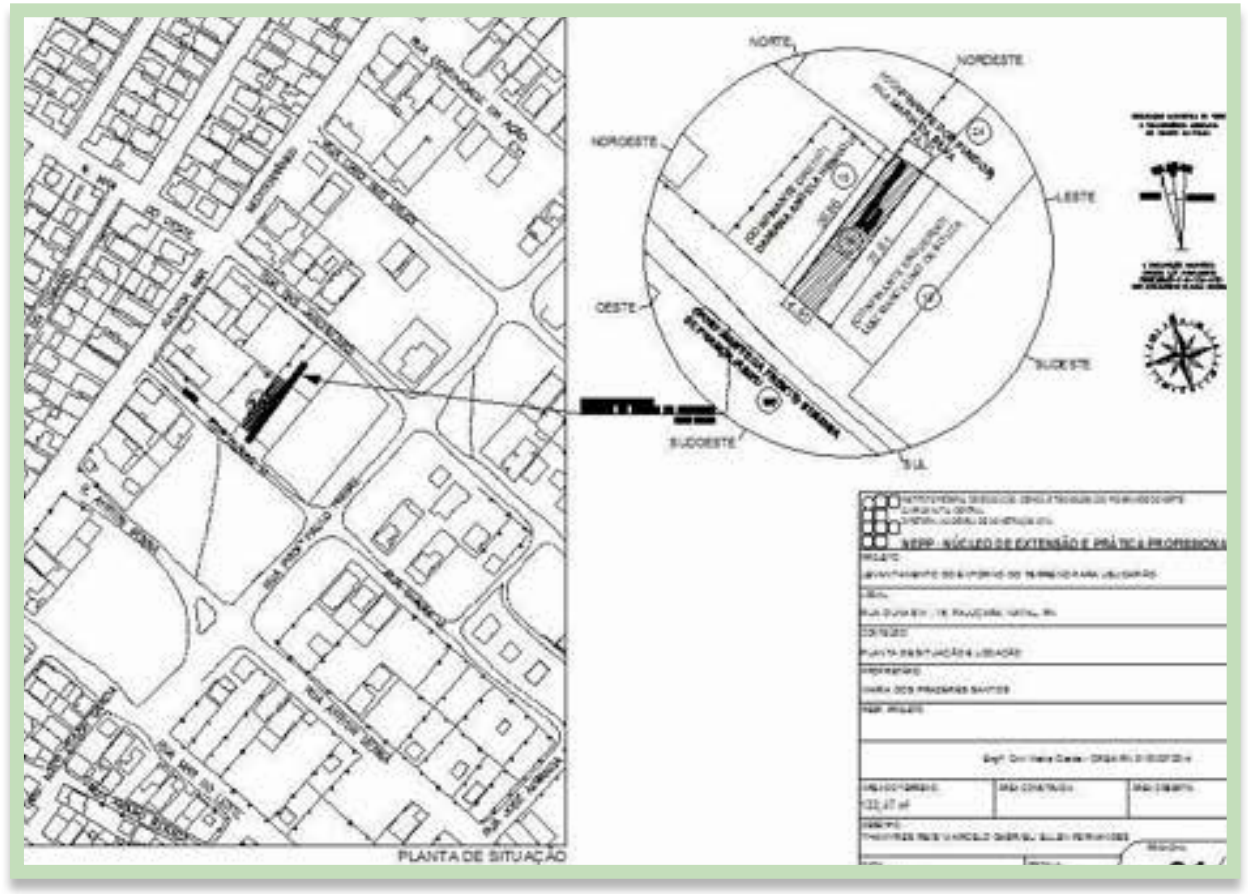

Figura 2: planta de situação e locação para atender a processos de usucapião

Para tanto, os alunos produzem as medições e representações gráficas através de softwares como o AutoCAD, o SketchUp, o 3DsMax e o Revit Architecture (Figura 3).

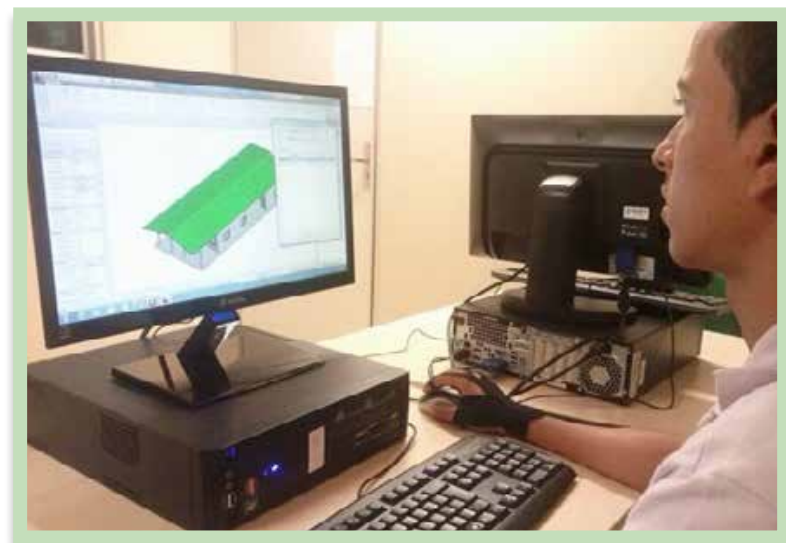

Figura 3: aluno produzindo projeto arquitetônico em Revit $^{\circledR}$

\section{REFERÊNCIAS}

INSTITUTO FEDERAL DE EDUCAÇÃO, CIÊNCIA E TECNOLOGIA DO RIO GRANDE DO NORTE - IFRN. Projeto político-pedagógico do IFRN: Uma construção coletiva. Disponível em: http:// portal.ifrn.edu.br/institucional/projeto-politicopedagogico. Acesso em: 5 de julho 2014. 